\title{
Republican Personality Cults in Wartime China: Contradistinction and Collaboration
}

\author{
JEREMY E. TAYLOR
}

School of Contemporary Chinese Studies, University of Nottingham (UK)

\section{INTRODUCTION}

In his recent book The Stalin Cult, Jan Plamper notes the importance of "contradistinction"-a concept used most often in the field of marketing - in the making of many mid-twentieth-century personality cults. Cults constructed around figures such as Stalin often incorporated attempts to deliberately contrast their objects of veneration with their rivals. This was manifest in the visual realm, in particular, where depictions of individual leaders were often created in direct contrast to those of their contemporaries. For example, "Stalin's pipe,” argues Plamper, “...was deliberately set off against the bourgeois cigar in general, and eventually against Churchill's cigar in particular. Roosevelt's optimistic, white-toothed smile ... was in deliberate contrast to Hitler's brooding, gothic countenance."1 Recent work on Mussolini suggests that this scenario is also known to historians of modern Europe; Christopher Duggan has shown, for instance, how the origins of the Mussolini personality cult can be traced to fascists' attempts to set their hero apart from Italy's liberal leaders in the 1920s.2 In writing on China the concept has been employed, though not articulated as "contradistinction," most often with reference to the cult of Mao Zedong. This can be seen in recent work by Daniel Leese, who, building on similar observations made decades earlier by scholars such as Raymond Wylie, has examined how modern China's most pervasive personality cult emerged out of a wartime desire on the part of Mao to emulate, but also set himself 
apart from, Chiang Kai-shek.3

The now burgeoning literature on the cultural history of China under Japanese occupation has started to revisit the wartime cults of other leaders,such as the much-maligned Chinese collaborationist leader Wang Jingwei. Several scholars studying Wang have moved beyond the biographical approaches that epitomized earlier studies4 to explore the political culture Wang fostered through his "Re-organized National Government (RNG) of China," from 1940 to 1945,including a distinct personality cult that was created around Wang himself. David P. Barrett, in the most succinct summary of this cult, described how, "Innumerable editions of Wang's articles and speeches were published; Ministry [of Propaganda] journalists followed Wang on his travels..., and major dates on the regime's calendar were celebrated in the towns and cities with meetings and march-pasts lauding the leader. Photographs of Wang in the press far eclipsed those of his subordinates."5

Yet to be fully explored is the extent to which this wartime adulation of Wang represented not merely a part of collaborationist state building, but a conscious attempt to undermine, and set Wang apart from, his primary rival Chiang Kai-shek. Much has been written about their decades-long personal rivalry.6 My aim here is to explore how the Wang cult that developed under the RNG was in many ways an exercise in contradistinction. As will become clear, attempts to distance Wang from Chiang not only influenced how Wang was presented but also how those around him justified his leadership of a rival government. We will see that such contradistinction also led Wang's government into a series of symbolic contortions toward the end of the war, when new allegiances and dynamics began to undermine the very notion of "peace" upon which Wang's regime had been rhetorically founded.

Beyond this, I will put forward a number of claims about the general nature of personality cults under the Japanese occupation. My first claim is that veneration of Wang Jingwei during 
occupation needs to be studied in a more objective manner than it has been, in the same way that cults constructed around other "puppet leaders" are now being revisited, a comparison to which I will return in my conclusion. I will argue that we need to reconceptualize "collaborationist" personality cults and reconsider the way in which they have been cast as mere wartime aberrations. Secondly, I shall explore how the peculiar circumstances of collaboration, in China and elsewhere, create a particular type of leader worship, one that is sometimes more understated and modest than that embodied in cults created around leaders who are remembered as champions of "resistance." It is regarding this second point that the concept of contradistinction becomes clearest, for as we shall see, by setting themselves against those that they have replaced, collaborationist leaders tend to construct a public image that is consciously less authoritarian than we might expect. Such contradistinction can only develop up to a point, however, since the leaders that are the focus of personality cults produced under occupation ultimately survive at the whim of the occupiers. That such regimes rely upon an external force often leads to confused or conflicting narratives about collaborationist leaders, and this ultimately undermines any legitimacy that such regimes might have initially claimed.

\section{THE JAPANESE InVASION AND THE CHIANG KAI-SHEK CUlT}

Much of the scholarship on the Chiang Kai-shek cult has emphasized the Nanjing Decade (1927-1937) as the crucial period in the construction of a public image around Chiang.7 It was during this era that many "cult products" 8 - portraiture, laudatory publications, statues—began to be manufactured and that Chiang's supporters most forcefully called upon the legacy of Sun Yat-sen to justify Chiang's status as the symbolic leader (though not head of state) of Nationalist China.9

However, my perusal of nearly all of the official propaganda produced in the months following the 1937 Japanese invasion suggests that the Chiang cult took on a decidedly new vigor 
in wartime. The general themes of patriotism and resistance are certainly important to understanding how the Republican state responded to war in 1937, and they have been thoroughly documented. But it is clear that party and state bodies devoted tremendous energy to calling for unreserved loyalty to Chiang (equating this with loyalty to China itself) and in redefining the Chiang cult to correspond with wartime realities. In the "Salvationist" press, Chiang's role in leading military defense emerged as a prominent feature of wartime reportage.10 As one Guangzhou-based editor of Chiang's wartime speeches phrased it in February 1938: "All those who resist the Japanese must profess to 'protect the supreme commander, Chairman Chiang' (yonghu zuigao lingxiu Jiang Weiyuanzhang). Anyone who opposes this [principle] will be seen by all the people as a traitor and will be vigorously attacked. Those who profess to protect [the supreme leader], must not take this merely as a slogan, but must remember the leader's orders, follow their guidance in everything they do, and never waiver."11

The elevation of Chiang to the status of not simply a military commander but the embodiment of resistance sparked an explosion of often-radical propaganda that drew on earlier representations of him as a military leader. This was most apparent in the work of the Political Department of the Military Affairs Commission (PDMAC; Junshi Weiyuanhui Zhengzhibu). This arm of the Nationalist state, restructured in January 1938, was managed by intellectuals such as Guo Moruo, but included artists of diverse political persuasions.12 The PDMAC remolded Chiang through posters, leaflets, movies, and print publications that called for total war against the Japanese, and raised Chiang to levels of veneration not witnessed during the Nanjing years. Of particular importance to the PDMAC's image of Chiang was his role in the Northern Expedition of 1926-1928, when he claimed to have defeated the warlords and created a unified Republican state. At the twelfth anniversary of the expedition's launch in June 1938 the PDMAC published hagiographic booklets that suggested, among other things, that patriots might like to send 
congratulatory messages to Chiang.13 At other times, it republished and distributed Northern Expedition-era texts about Chiang, and celebrated his role in unifying China and defeating foreign imperialism a decade before the Japanese invasion.14

The PDMAC's visual representations of Chiang were similarly stark and militarized, and betrayed the influence of European fascist propaganda. Chiang was presented only in military uniform, with his face often superimposed above anonymous Nationalist soldiers. His images usually struck a combative pose, often while in the throes of oratory. He rarely smiled (figures 1 and 2).

Tellingly, the production and distribution of this image of Chiang was not limited to the PDMAC or even to the Nationalists per se; leftist artists who had risked imprisonment prior to 1937 for their caricatures of Chiang spent the early months of the war rendering flattering images of him for propaganda purposes.15 As Lyman van Slyke has noted, the very nature of the United Front determined that "Communist propaganda organs praised Chiang ... and proclaimed their determination to resist to the end beside the Central Government...."16 In late December 1938, a "Protect Chairman Chiang Rally" was held in the de facto communist capital of Yan'an,17 and in communist base areas his portraits were often hung beside those of Mao Zedong and Sun Yat-sen (figure 3).

As this reference to Sun Yat-sen suggests, the early wartime promotion of Chiang differed from that propagated during the Nanjing Decade in another key respect: Expressions of fealty to Sun and his 1911 revolution had been a central platform of the KMT Chiang cult in the 1920s and 1930s, when they were used to highlight Chiang's claims to legitimacy. The construction of the monumental Sun Yat-sen Mausoleum in Nanjing in the late 1920s and its transformation into "one of the most sacred sites in modern Chinese history" is but one example, and it laid the foundation for what some have called a "spatial link" between Sun and the city of Nanjing.18 The cult of 
personality that developed around Sun following his death in 1925 was inextricably linked to the political culture of prewar Republican China and the rise of Chinese nationalism. Drawing on precedents as far ranging as Abraham Lincoln and Vladimir Lenin, it transcended partisan politics despite being actively cultivated by the state. The cult was manifest in all manner of public displays of allegiance to Sun, and became central not only to the Nationalist Party, but more generally across competing understandings of modern Chinese history.19

From 1937 onward, veneration of Sun, while still important in Nationalist rhetoric, was balanced with veneration of Chiang. In lists of early wartime slogans (biaoyu) published by the PDMAC and the Nationalist army, for example, Chiang was the only leader directly referred to, with resistors invariably being instructed to "protect the supreme leader, Chairman Chiang" (yonghu Jiang Weiyuanzhang) (figure 4).20 Chiang's face was attached to military medals bestowed upon heroic resistors, and his name given to rifles of Nationalist soldiers. 21 His loyalty to Sun was never denied in any of this, but it was clear that the invasion had led to a rapid and unprecedented foregrounding of Chiang in Nationalist political culture. In the pantheon of Chinese strongmen, Chiang sat alongside Sun rather than below him.

This shift was most tangible in the wartime rewriting of laws on the production, distribution, and use of Chiang's image and name. While such laws had existed from the early years of the Nanjing Decade and had been observed within the ranks of the Nationalist Party, many were reinforced on a national scale in 1938. In July of that year the Executive Yuan promulgated new regulations that specified precise ways and contexts in which portraits of the zongcai (lit. "director general"-i.e., Chiang) and the chairman of the National Government were to be hung in government offices. Later rules designated how Chiang was to be referred to in writing.22

This institutionalization of the Chiang cult was partly a direct response to the hurried production of Chiang imagery and texts in the weeks and months after war broke out, when 
urgency compromised the unity of the message that groups such as the PDMAC promoted. A cynical interpretation might suggest that such regulations were an opportunistic effort by Chiang and those around him to stifle the factional divisions that had plagued the KMT before 1937 and bring the cult to a truly national audience.

In any case, by the time Chiang's armies arrived in the city of Chongqing in late 1938, and despite various military setbacks that had befallen the Nationalist state, Chiang Kai-shek enjoyed a public persona in "Free China," and an ability to determine and control that persona, that greatly surpassed with the hagiographic representations created around him just a few years before. In Chongqing, Western observers noted with some incredulity that his supporters now saw him as “almost superhuman.”23

\section{The EMERGence of THe Wartime Wang JingWei Cult}

On the eve of his controversial departure from Chongqing in December 1938 and at the start of his peace negotiations with the Japanese, the Nationalist Chinese premier Wang Jingwei had been witness to and involved in the creation of Republican Chinese leadership cults for as long as any living politician. A protégé of Sun Yat-sen in the 1910s, Wang had been one of the most enthusiastic architects of the Sun cult (having helped draft Sun's political testament, for instance,).24 As a career revolutionary, Wang had also been the focus of celebration by sections of the Kuomintang. In the late 1920s, for example, he had been the object of adulation from that party's "Reorganization Faction" led by Chen Gongbo, which had openly called for the overthrow of Chiang Kai-shek.25 Wang has even been described as having been a sex symbol in prewar China, and he was certainly famed for his charisma and looks.26 Despite his long-term rivalry with Chiang Kai-shek, Wang in his capacity as the nation's premier had acquiesced in the wartime promotion of Chiang.

Wang Jingwei's desertion from Chongqing, however, marked a new and very different stage 
in the creation of his public image. Over the course of 1939, Wang discussed the possibility of establishing, with Japanese backing, a new, alternative government to Chiang Kai-shek's. The very prospect of such a government represented the first time that Wang and his long-time followers, particularly the newspaper editor Lin Bosheng and the journalist-cum-hagiographer Tang Liang-li, would enjoy a foreign power's support in promoting their leader on a quasi-national scale. Yet, at the same time, and in a manner much like other collaborationist leaders such as Vidkun Quisling in Norway,27 there were many points during Wang's fraught discussions with the Japanese when his hypothetical regime might never have been realized, or when the Japanese appear to have dangled the possibility primarily to coax Chiang Kai-shek into direct negotiations.28 The promotion of Wang thus proceeded in "stops and starts" throughout 1939, and it often lacked any unitary, focused message about him or his suitability for national leadership.

This highly unusual context influenced the organic fashion in which Wang began to be promoted in early 1939, by both the Japanese and Chinese members of the "peace movement" around him. One can point to no single date as the "start" of the wartime Wang personality cult, and no set of rules was published that either group was expected to adhere to. It is nonetheless significant that Wang's promotion as an alternative to Chiang began more than a year before his regime was officially inaugurated. It thus developed with no formalized set of regulations concerning how Wang was to be pictured or even referred to, and the result was a polyphonic and decentralized cult within which vastly different interpretations of his significance sometimes competed. This lack of a unified message about who Wang was, what he signified, or even what he looked like posed problems for Wang's courtiers, particularly from late 1941 onward.

That said, Wang's initial departure from Chongqing did inspire a burst of hagiography, primarily under the auspices of Lin Bosheng's newspapers in Hong Kong,29 but also via Japanese army artists. One early example was an illustrated booklet produced in January 1939 by a 
Japanese-backed propaganda organization in Beijing under the title Se yanjing (Colored spectacles). Its text and cartoon-like images tell the story of an optometrist's store owned jointly by Chiang Kai-shek and Mao Zedong, who are selling "kangRi yanjing" (anti-Japanese glasses) to anyone willing to buy. Wearing these spectacles, the people of China are oblivious to the corruption of the Nationalists and communists, but are willing to run blindly into battle as cannon fodder. Only Wang Jingwei sees through the ploy, and smashes his tinted spectacles on the ground with the words, "I don't want these!" This allows him to see the glorious future that collaboration promises (figure 5).30

Very different images of Wang were being developed at this time. Anonymous propaganda leaflets, also produced that January and seemingly distributed by the Japanese army, included a portrait of a sober and pensive Wang alongside texts authored by him calling for peace. Such propaganda drew on historical references from Chinese antiquity and was couched in a far softer rhetoric, which called on the KMT to "seriously reflect" (fanxing) on its decision to continue with resistance. 31

More subtle promotion of Wang was found in pro-Wang editorials published in newspapers managed by Lin Bosheng. It was through newspapers such as the Central China Daily News that "the noble personality of Wang and his followers, who sustained nationwide condemnation and worked for the peace movement without personal benefit" began to appear with some regularity in early 1939.32 The narrative that emerged in the pro-Wang press in these early months embraced the very controversy of Wang's decision to even speak with the Japanese. It deployed this act as evidence of Wang's spirit of self-sacrifice, while always casting a pacifist, patriotic, and anti-communist Wang as the antithesis of Chiang.33 As Andrew Cheung has observed, the key distinction made by individuals such as Lin was that Wang was a "constitutional leader" (and an upholder of the Republican government) in contrast to Chiang Kai-shek, the dictator.34 
Many regimes had faced the problem of legitimizing "puppet leaders" prior to the foundation of the RNG, and so there were a number of precedents that Wang and his followers might have drawn upon in this early period when trying to establish a credible public persona for their leader. In Soviet-occupied Xinjiang, a personality cult had been built around the Chinese warlord Sheng Shicai, who ruled with Soviet backing from the mid-1930s onward. It was based on the myth of equality between Sheng and Josef Stalin, with "huge portraits" of both men decorating public spaces in the province.35 Similarly, the "Provisional Government of the Republic of China," which had been (re)established in occupied north China in 1938, had worked hard to promote of its nominal leader, Wang Kemin. Wang became the object of scorn in the Western press, yet his short-lived regime produced images in posters and leaflets of a gargantuan Wang towering over the "north Chinese" masses as they waved the five-colored flag of the provisional government, in an attempt to instill loyalty to the unaccomplished nationalist bureaucrat.36

Over the course of 1939, the promotion of Wang Jingwei progressed in quite different fashion. There appears to have been a deliberate effort to avoid mistakes associated with the promotions of these earlier "client regimes," and specifically to ensure that Wang Jingwei did not become “another Wang Kemin.”37 For this reason, his Chinese supporters were given significant autonomy in encouraging public adulation of their hero. Some American observers noted that Wang "and his cohorts" had "stolen the show" from the Japanese by virtue of their far keener understanding of their Chinese audience. 38 Nonetheless, Wang's Chinese courtiers could not claim complete control over his image, since prior to March 1940 no single person, agency, or group was charged with managing his promotion. As a result, one finds Wang's name and image being used in laissez-faire fashion in the lead up to March 1940. He was presented as a militant revolutionary by one source, only to appear as "cute and cuddly," or manga-esque in another. Unusually for a mid-twentieth-century Chinese leader, Wang was in early 1940 even used to 
market medicinal products.39

\section{CONTRADISTINCTION AND THE WANG CULT}

David P. Barrett has argued that Wang Jingwei's RNG was unique among modern Chinese regimes in its efforts to highlight its continuities with the government it sought to replace, inheriting many of the same symbols and policies the Nationalist state had developed in the Nanjing years.40 Margherita Zanasi has similarly described the collaborationists' ability to resurrect Republican Chinese iconography under Japanese domination as a political victory on the part of Wang Jingwei.41 The RNG certainly did derive much of its rhetoric, and even its name, from particular strands of prewar Republican nationalism, most noticeably the Reorganized Faction within the KMT. Wang and others who followed him back to Nanjing in 1940 had belonged to that faction, and so it was no coincidence that his wartime regime adopted a similar name.42

Texts produced in support of Wang around the time of his regime's official inauguration in March 1940 suggest that in style, if not in content, the wartime Wang cult drew deeply from the reservoir of PDMAC hagiography written around Chiang. Many of the titles and phrases attached to Chiang since the mid-1930s were appropriated by Wang's propaganda chiefs from 1940 onward. Ordinary people in the occupied zones were called upon to "protect Chairman Wang" (yonghu Wang Zhuxi), "follow the leader" (fucong lingxiu), and submit to the will of their "supreme leader," (zuigao lingxiu) just as those in "Free China" had done for Chiang Kai-shek.43 Collections of Wang's speeches were edited on the model of those crafted around Chiang in 1938-1939. His portraits were distributed both internally and to parts of occupied Asia,44 where members of diasporic Chinese communities were expected to hang them in public and make a show of their hatred for Chiang Kai-shek while doing so.45

In the centrality of Wang to his regime, the RNG looked like not only the Chinese government 
it had replaced but also other "client states" that predated it (though in other ways those regimes were very different). For instance, recent work on propaganda produced in the Japanese-sponsored Manchukuo has shown that the "Manchurian emperor" Puyi was the only identifiable "character" in wartime documentaries "otherwise populated by collective heroes."46 As would occur with Wang Jingwei, state propaganda organs in Manchukuo promoted Puyi as the living embodiment of a state ideology, "the concrete expression of the spiritual foundation" of "the Kingly Way" (Wang dao). 47

Tellingly, the celebration of Wang as part of the inauguration of the RNG was derivative of, but also defined directly against, the early wartime cult of Chiang Kai-shek. Although some of the methods the RNG utilized resembled Nationalist adulation of Chiang in Chongqing, the promotion's content differed noticeably, as did the extent to which such adulation was expressed. As Andrew Cheung has noted, this meant casting Chiang as a "dictator" while praising Wang as a symbol of constitutionalism. RNG propaganda was founded on a seemingly counterintuitive logic that Wang deserved praise precisely because he did not seek it.

While a focus on constitutionalism and public self-effacement were consistent with earlier propaganda built around Wang by his supporters within the KMT, and particularly by the party's Reorganization Faction, the RNG consciously used the same approach to accentuate Wang's differences with Chiang in wartime. Lin Bosheng phrased this distinction at the first RNG propaganda conference in the summer of 1941, when he reminded his staff that "we need to overthrow the politics of individual dictators [i.e., Chiang Kai-shek]," because, "outwardly such people call on the need for centralized rule, but in reality they are simply dictators, who have never had any concern for the ordinary people." Wang was presented in contrast, as a selfless leader who was fully aware of the risk he was taking in choosing to "collaborate," but did so anyway to keep China intact.48 
In this regard, the Wang cult shared much with Pétainism in occupied France. Despite their differences, both Marshall Pétain and Wang Jingwei were marketed by those around them with an obsessive attention to their centrality in national politics and their association with Republican ideals. In both cases also, there was an important attempt to emphasize continuities between their legitimacy pre- and post-invasion. Both men were praised for their willingness to serve rather than any inherent power or greatness. In occupied France, this meant presenting Petain as "reluctant martyr rather than incipient dictator."49 For hagiographers such as Lin Bosheng, it meant drawing a clear line between dictatorial Chiang Kai-shek and "Mr Wang [whose] desire to love and protect his country is without precedent."50

Much effort was put into encouraging contradistinction between Wang and Chiang on precisely this latter point. In internal directives on propaganda, for example, RNG bureaucrats were encouraged to cast Wang with Chiang as direct opposites: "We should make a distinction (liang xiang duibi) between the Nationalist Government [i.e., the RNG], which loves and protects the people, and Chongqing, which sacrifices the people. This will enable the people to realize who is their protector, and who is their enemy."

This was also communicated in the visual realm. At the most basic level, imagery created around Wang in early 1940 stressed his civilian credentials: official portraits (produced by, significantly, private studios rather than state photographers) showed Wang in a tailored suit, in clear contrast to the always-uniformed Chiang. In public Wang appeared in a full array of civilian costumes: a dark tailored suit, a white linen suit, a Chinese scholar's gown, or, on official occasions, a morning suit (figure 6).51 Wang's full head of hair was no more manufactured than was Chiang Kai-shek's close cropped, military-style haircut, yet much was made of their differences in grooming. In early RNG photography, Wang's hair was always immaculately oiled and combed, while in graphic art the fullness of his hair was accentuated. Both Japanese and RNG 
propagandists made much of Chiang Kai-shek's apparent baldness, believed to be a symptom of his lack of virility (figure 7). In all of this, the RNG drew on a longstanding public image of Wang, which had been fostered by his followers within the prewar KMT, as a man of "consummate elegance and taste."52 In the context of the Second Sino-Japanese War, this narrative was highlighted to contrast Wang with the ever-uniformed Chiang.

Though Wang was frequently presented in oratorical poses, as Chiang had been, he was usually pictured in far less aggressive mode than Chiang, and he often wore a smile.53 Official portraits of Chiang in this early phase of the war showed the generalissimo gazing into the distance, but Wang's eyes often looked directly at the viewer, which harkened back to prewar Sun Yat-sen iconography. Much was also made of the two men's distinct speech differences. Despite Cantonese intonations, Wang spoke in a Mandarin that was far closer to what today would be termed standard "putonghua" rather than the Ningbo-laden Chinese identified with Chiang. This is one reason Wang's voice was used more often in official RNG broadcasting than was Chiang's in Chongqing.

Even Wang's status as husband and father was promoted in very different ways from Chiang's. Chiang Kai-shek's government gave much attention to his English-speaking wife, and the promotion of Madame Chiang as a maternal protector of Chinese soldiers was a mainstay of Nationalist propaganda early in the war.54 Axis propaganda besmirched Chiang for this same reason, however, presenting him as a hen-pecked husband or the partner of a coquette. It is therefore noteworthy that Wang Jingwei's wife Chen Bijun—an accomplished Republican activist in her own right—was nearly absent from RNG visual propaganda except for occasional references to her in the print media.

While the RNG constructed a markedly different story around Wang through visual imagery, it also distinguished itself from the Chiang "dictatorship" by distancing itself from the more 
extreme forms of leader worship that had characterized KMT political culture during the Nanjing years. A standard feature of both the Sun and Chiang personality cults, for instance, had been naming public institutions or thoroughfares after them. It is thus noteworthy that no streets or institutions were given Wang's name under the RNG, and thoroughfares that had been named in honor of Chiang prior to 1937 were not renamed after Wang. Even when Japanese occupiers removed Sun Yat-sen's name from public spaces in cities such as Xiamen, they did not replace it with Wang's.55 Wang also refrained from lavishly celebrating his birthday, in contrast to Chiang, whose birthdays in the 1930s had been marked by public expressions of adulation. Nor was Wang's image reproduced on RNG banknotes, in favor of artistic representations of the architectural symbols of his regime such as the Sun Yat-sen Mausoleum.

Furthermore, the RNG was cautious about the manufacture of immovable "cult commodities." We know that Wang was gifted with bronze busts of himself during visits to regional cities beyond Nanjing as early as 1941,56 but when local elites in Suzhou decided in March 1943 to do what such groups had often done for Chiang Kai-shek before the war and commission a bronze statue of the RNG leader, Wang himself asked that "an immediate stop be made to the plan."57 This may well have been due, as Wang's enemies claimed, to RNG fears that such statues would be subject to iconoclasm, or their worries by this stage in the Pacific War about the long-term prospects for the RNG itself.58 Be that as it may, the result was a far subtler and less visually dominating cult than that promulgated around Chiang in Nanjing or after the Second Sino-Japanese War broke out. The only statues of Wang erected during the war were some created hastily in Chongqing so as to allow city residents to spit on this "traitor" in absentia.59

What all of this suggests is that the RNG propaganda appeals to constitutionalism were more than mere rhetoric, and served to highlight continuities between the RNG and the "Reorganized" tradition within the KMT, at least at the regime's outset. Here it is instructive to compare the 
regulatory regimes surrounding representations of Chiang Kai-shek in Nationalist territory with laws introduced from March 1940 onward regarding representations of Wang Jingwei. A key feature was that the RNG did not proscribe how Wang was to be represented. To be sure, Lin Bosheng and his cadres were keen to present a particular narrative that stressed Wang's supposed selflessness. In RNG law, however, it was the position of "Chairman of the National Government,"rather than the individual who occupied it, which was held in greatest esteem, and this determined how a person was to be treated or spoken to. While Wang's public calls for Lin Sen to "return" to Nanjing in 1940 and take up the position of head of state have often been skeptically dismissed as a mere political stunt,60 they in fact pointed to a key difference between the Wang and Chiang personality cults. Rhetorically, RNG adulation of Wang was based not on charisma, but rather on his suitability as nominal head of state and his claims to be the inheritor of Sun Yat-sen's "Chinese revolution." Contradistinction thus went far beyond visual, aural, or even narrative representations of Wang, and determined how the RNG constructed the Wang personality cult. If Chiang was presented as a war hero blessed with "superhuman" powers and brilliant personal attributes, then Wang was to be promoted as a reluctant patriot.

In this respect we find further parallels between the Wang cult and Pétainism, for just as Nicholas Atkin has argued, that Vichy propaganda was very much "a French experiment" (rather than something foisted upon France by the Third Reich),61 the Wang personality cult drew overwhelmingly on Chinese political traditions. RNG propagandists employed early wartime precedents of leader worship, but also strove to defend their actions as fitting neatly within a Republican Chinese narrative, despite the many references to Pan-Asianism and Sino-Japanese cooperation. As the RNG itself argued, the anti-Chiang vitriol of wartime Nanjing had precedent, having been central to the political activities of Wang's Reorganization Faction in the 1920s.62 Anna van der Goltz and Richard Gildea's argument that the Pétain cult was the natural result of a 
political culture that encouraged the worship of "strong men," rather than a wartime aberration, can be extended to occupied China.63

By far the most important illustration of attempts to contrast Wang the inheritor of Republican Chinese tradition with Chiang "the dictator" was the prominence RNG political culture gave to the figure of Sun Yat-sen. RNG logic posited that adoration of Wang was not an end in itself, but would manifest love for the Republic's nominal founder and, by connection, the very idea of the Republic. This sentiment was found in all manner of Wang-related propaganda, including most of Wang's public utterances, which invariably cited Sun in some form. The strategy was initiated well before March 1940,64 but is clearest in an RNG propaganda directive from 1942, which argued, "Chairman Wang is the only disciple of Sun Yat-sen; if citizens of our country wish to respect Sun Yat-sen, they must protect the Chairman."65 In some cases, RNG propagandists even referred to Wang as a "second Sun Yat-sen."66

One cannot overstate the importance of Sun to the Wang cult in RNG China. Others writing about the collaborationist regime have noted the veneration of Sun, often cynically, but the RNG's adoration of him surpassed that during the Nanjing Decade.67 And how could it have been otherwise? Wang's entire political career had been linked, if not to Sun Yat-sen himself, then to Sun's legacy, and this is why Wang was such an attractive prospect for the Japanese in 1939. "In the history of the Chinese revolution," wrote an anonymous RNG cadre, "Mr. Wang is the longest serving follower of Sun Yat-sen, and we can say that only Mr. Wang is able to continue the revolutionary task of the late premier ...." 68 Under Wang, the dates of Sun's birth and death were officially commemorated annually, and construction of bronze statues of Sun, funded by either municipal authorities or private donations, continued apace. In all of this, the RNG again contrasted their leader with Chiang Kai-shek: while Chiang's dictatorial qualities could be found in Chongqing's gradual replacement of Sun images with Chiang's, the RNG remained steadfast in 
its loyalty to the "father of the nation"; while the Nationalists evoked the memory of the Northern Expedition for inspiration, the RNG looked to the ideas and revolutionary zeal promoted by Sun and Wang in the heady days of the early Republic.

Of equal importance was the RNG's possession of cities such as Nanjing (and, to a lesser extent, Guangzhou and Wuhan) and the "symbolic capital" associated with Sun in and around them. Within Nanjing, the Sun Yat-sen Mausoleum became the most important symbol of the Wang regime and its premier "landmark." Visits to the mausoleum became an integral part of RNG political culture, and the site was the most popular backdrop to imagery of Wang himself.

Such depictions not only stressed claims of Wang's symbolic closeness to Sun, but also displayed the centrality of land and national territory to RNG ideology. As recent comparative studies have shown, this was a common thread in other collaborationist regimes as well, most noticeably Vichy France, which saw attachment to national territory as a central tenet of what a number of historians have deemed "collaborationist nationalism."69 The RNG may not have gone quite as far as Vichy went in linking its leader to symbols of French nature and the earth. For example, I have yet to find an instance of Wang's name being attached to a specific tree, as Pétain's was.70 Yet there can be little doubt that the frequent picturing of Wang in and around the physical space of Nanjing signaled an RNG obsession with national territory. Wang differed from Chiang precisely because he had physically "returned to the capital (huandu)."

Nanjing had been redesigned for Sun in the 1920s as an urban monument writ large, and the RNG's preoccupation with the city and its use it in the construction of the Wang cult, expressed above all a desire to stress Wang's symbolic connections with Sun.71 Even here elements of contradistinction can be found, however. Rudolf Wagner has shown that Wang's wartime possession of Nanjing, and the mausoleum therein, were insufficient: The RNG "needed a very particular marker to set it off against Chiang Kai-shek's." It found this in the form of Sun Yat-sen's 
preserved entrails, which had been left in Beijing after his death and the RNG now relocated to Nanjing among much pomp. Wang's ability to reconstitute Sun's physical body in Nanjing during the war years was premised on RNG propaganda—Sun's "sacred entrails" were worked into RNG political ritual—and set his regime apart from a government that had chosen not to relocate Sun's body to the interior when it fled the national capital in December 1937.72 In RNG hagiography, Wang's physical proximity to Sun's preferred site of China's capital, and to Sun's corporeal remains, made him a far more suitable candidate to lead Sun's Republic.

\section{Changing Cults in Changing Contexts}

While the literature on the Japanese occupation of China has emphasized the importance of "peace" in RNG rhetoric, the visual record reveals a far more complex situation with regards to the post-1940 promotion of Wang Jingwei. As with much else concerning the Second Sino-Japanese War, the transformation of this conflict into the Pacific War in December 1941 represented a watershed in how both Wang and Chiang Kai-shek came to be defined and promoted by their respective regimes. For the RNG, this event represented a crisis of legitimacy and undermined its raison d'être, for it brought into question the extent to which Wang could continue to stand for peace or justify his collaboration with the Japanese on such grounds.73 The resulting shift in the relationship between Wang's regime and its protector would also change the ways in which Wang himself was promoted, which transformed him into a leader who appeared remarkably similar to the early wartime depictions of Chiang. Ironically, though for similar reasons, the same period brought a concerted effort on the part of Chongqing to reinvent Chiang as a statesman rather than as simply a military leader.

Photographs of Wang in military uniform were being distributed through the RNG press as early as 1941. The "rural pacification" (qingxiang) campaigns that the RNG had instituted that year had often been documented with images of Wang dressed in a field uniform inspecting the 
progress of attempts to root out underground resistance organizations. In his role as nominal head of state, Wang had also partaken in military parades (yuebing), dressed in formal military attire, and sometimes wearing a uniform, at times while being photographed in front of civilian portraits of himself. While such martial images were at odds with the far more common narrative of Wang as a civilian leader, their association with anti-resistance campaigns meant they did not necessarily undermine the wider appeals to pacifism inherent in the Wang cult.

Official RNG publications produced after the Pearl Harbor attack, however, reveal new discursive problems the RNG faced when promoting its leader in a war that now pitted its protector Japan against the Allies - the facade of pacifism became harder to maintain. Their confusion is evident in an RNG Ministry of Propaganda report published in March 1942 to mark the second anniversary of the regime's founding. Here, two very different Wangs are presented to the people of occupied China: the frontispiece includes a prominent portrait of Wang identical to those produced in 1940, while other sections celebrate a stern, uniformed, and remarkably Chiangesque Wang as "Chairman of the Military Commission" (junshi weiyuanhui weiyuanzhang) (figure 8).75

In contrast to the public expressions of reverence for Wang as a peacemaker in the spring of 1940, military parades of the sort that had long been associated with Chiang now became a regular element of Wang's public appearances. As the rhetoric of peace gave way to anti-European tirades couched in the language of "pan-Asianism," the RNG propaganda apparatus made a clear decision to associate Wang with both armed resistance to imperialism and peace, a split that has often gone unnoticed in studies of RNG propaganda.76 Wang took on a pictorial association with the RNG navy,77 in particular. This may have been meant to mark a contrast with the obsession the Chongqing Nationalists displayed for aviation, though it was more likely because the RNG controlled much of China's eastern seaboard. Wang was photographed in naval uniform not only on military occasions but even when visiting civilian sites, such as during his October 1942 trip to 
the Beijing Confucius Temple.78 He wore the same uniform in an updated and then much reproduced portrait photographed in Nanjing that year, in which his full head of civilian hair was far more closely cropped than it had been in 1940 .

Photographs of a grinning Wang Jingwei sipping cocktails with Nazi diplomats—used so often in critiques of him during and since the war-are not representative of the image typically projected within China at the time. What became the mainstay of the post-Pearl Harbor period were images of a solemn and uniformed Wang, often observing passing troops or saluting his people as they prepared to take up arms against Churchill and Roosevelt. This portrayal peaked in the explosion of pro-Wang propaganda that accompanied the RNG's official declaration of war on the Allies in September 1943. During this interim period Wang made a remarkable number of public appearances at events commemorating past acts of armed bravery by Chinese patriots, such as the widely celebrated, August 1942 centenary of the outbreak of the Opium War (figure 9).

Wang's new image was as a military leader who could stand alongside other Japanese-supported resistors of imperialism, from Subhas Chandra Bose to Sukarno. This was part of more aggressive attempt to instill blind loyalty to Wang among the RNG public in a fashion reminiscent of some of the most authoritarian wartime regimes. In 1942, for example, propagandists tried to promote an ideology they called "Wang Jingwei-ism" (Wang Jingwei zhuyi), predating the term "Mao Zedong Thought" (Mao Zedong Sixiang) coined almost a year later in Yan'an.79 They defined this as a combination of Sun Yat-sen's “Three Principle's of the People": pan-Asianism, pacifism, and realism.80 More significantly, and presaging propaganda techniques that became commonplace in China decades later, in the summer of 1943 the RNG Propaganda Ministry ordered the production and compulsory wearing of badges bearing Wang's image as a means of "expressing respect and esteem for our one and only leader." This borrowed leader-worship techniques from other "advanced countries" (possibly the Soviet Union),81 and 
arguably marked the peak of the Wang cult in terms of its public reach. It was probably the furthest the RNG went in trying to enforce support for Wang's leadership: "Come on!" called RNG propagandists, "Let's make sure that the Chairman's image can be seen on every collar!"82

The promotion of Wang as a strongman, alongside continued rhetorical reverence for him as a maker of peace, was even more remarkable for occurring precisely as Chongqing was changing how it promoted Chiang Kai-shek to the people of "Free China." Indeed, it appears to have developed in direct response. Wang Ke-wen, for instance, has written that Wang envied the attention the Allies lavished upon Chiang after Pearl Harbor, and resented that he had not been granted a similarly prominent a position in Axis propaganda.83

For the Chongqing Nationalists, Pearl Harbor quickly generated a new, unprecedented international angle to their leader's profile, and the shift that followed also brought access to news media, technologies, and techniques that had previously been scant. As a result, the image of Chiang that was promoted both domestically and abroad over the next two years looked remarkably different from the militant war hero of 1938-1939. "Chiang as statesman" was an international leader who undertook official visits to British India and sat alongside Allied leaders in Cairo. He still wore a uniform and talked of fighting the enemy to the bitter end, but in much of this period's portraiture he was photographed in a Chinese scholar's gown, smiled for the press, and was made to project a far more pensive, perhaps even meditative pose.

This reinvention of the Chiang cult reached a peak in later 1943, and specifically with Chiang's appointment that August as Chairman of the National Government. The event culminated in the production and dissemination of a set of new official portraits of him dressed in full, honorific military uniform (rather than the far more Spartan field uniform associated with his public image in 1937-1938), and staring directly at his admirers with the gaze of a statesman rather than that of a warrior. In other cases, Chiang was pictured by his own court photographers 
and by the photojournalists of the Luce media empire in a serene and patrician mode. This persona is exemplified in the star-struck writings of one American supporter who praised Chiang in 1943: "He now seems little older in body ... but the years have left a clear impress on his moral character. To the sharp discipline and authority of the soldier he has added the characteristics of a teacher—reserved kindliness, a daily preoccupation with moral questions...."84

Such promotion of Chiang as a "teacher" and statesman coincided with the publication of China's Destiny, a book in which Chiang described himself as "being identified with restarting the Republic of China on the road to freedom and independence."85 It was marketed by the Chongqing Nationalists as “the most important book written since [Sun Yat-sen's] Three Principles of the People."86 The book was such a powerful tool of Nationalist propaganda that Daniel Leese has argued it directly contributed to the beginnings of the Mao Zedong personality cult, with the Chinese communists both inspired and appalled by the extent to which Chongqing was willing to go in promoting Chiang as a leader, ideologue, and implied challenger to the Sun Yat-sen legacy.87 Its publication was equally significant for collaborators, for in RNG efforts to promote Wang as a loyal disciple to Sun, rather than as a thinker in his own right, Wang had never produced an ideological opus of this sort.

This late-war Chiang was a product as much of good timing as of the efforts of Nationalist propagandists. He was only able to assume the mantle of head of state due to the August 1943 death of then-chairman of the Nationalist Government Lin Sen. Lin's demise in Chongqing brought a sudden hiatus in the iconography of the Nationalist state, one Chiang loyalists lost no time in filling. By the end of 1943, for instance, the Central Ministry of Propaganda (Zhongyang Xuanchuanbu) had published new regulations governing the hanging of portraits of national leaders. These reinforced 1938 regulations, but also specifically stipulated the removal Lin Sen's portraits from public offices and their replacement with those of Chiang as the new head of state. 88 
That December, regulations were put in place to control the production of portraits and sculptures of Chiang and Sun Yat-sen by non-governmental individuals in "Free China." These rules, far more extensive than any introduced previously by either Chiang's government or the RNG, included requirements that artists submit detailed plans of their work to the Ministry of Propaganda for approval before completing or distributing them. The artists also had to submit extensive information about themselves. 89

The shifting dynamics of the war after Pearl Harbor thus turned the Wang-Chiang binary on its head. A new network of allegiances engendered when World War II came to China led directly to the transformation of Chiang's China from a stand-alone enemy of Japan to a member of the "big four" and a subsequent reinvention of Chiang's public image both within China and abroad. For the RNG, it prompted a confused and hurried attempt to carve out a symbolic space for its leader within the Axis bloc, which drew on a full array of authoritarian propaganda that it had previously been so keen to avoid.

\section{CONCLUSION: PERSONALITY CULTS UNDER OCCUPATION}

For much of their political careers, both before and during the war against Japan, Chiang Kai-shek and Wang Jingwei sought to present themselves in vastly different ways. During the war years, Wang acquired a centralized propaganda apparatus and staff that enabled him to challenge Chiang's preeminence. But the origins of his wartime cult, and the far more amorphous way in which it was promulgated, generated often-conflicting portrayals and views of who Wang was and what he stood for.

Examining the wartime Wang cult at its height in March 1940, we find that Wang took on an unusual glow in the pantheon of Second World War leaders. In seeking to employ the standard methods of leader worship available in Republican China, and at the same time to write an original "story" about their leader, RNG propagandists succeeded in producing a personality cult that, 
through most of its existence, avoided the excesses of leader worship being promoted in "Free China." Wang was not a democratic leader, but his promotion in occupied China was far more modest and open to individual interpretation than was the strictly controlled promotion of Chiang Kai-shek. As I have shown, this was a key element of the RNG argument, for its central aim in creating the cult was to set Wang apart from Chiang in both form and intent.

The competition between these two rival Republican Chinese cults can teach us much about the worship of "great men" under regimes of occupation. Much of the general literature on personality cults notes the tendency toward veneration of heroic leaders as a form of "symbolic legitimation" in states beset by "social conflict," or "where there is low consensus on ideological and programmatic goals," often corresponding with times of war.90 There has been less study of the peculiar circumstances that confront regimes built around "great men" in the shadow of an occupying power, even though Asia and Europe saw many such regimes come and go during in the course of the twentieth century. Too often, attachment of the label "collaborator" to such regimes has resulted in their being deemed unworthy of serious study.

The Wang cult highlights the problems inherent in balancing a national and supposedly autonomous political movement with the ever changing political needs of an occupying power. Here the fate of the Wang cult falls into a pattern common to many "client regimes," including those in vastly different geographic contexts.

Throughout this paper, I have alluded to numerous parallels between the wartime Wang cult and that of Pétain in Vichy France. When considering the post-1941 fate of the Wang cult, however, perhaps the most striking comparison can be drawn between the RNG and a series of short-lived personality cults in Soviet-Occupied East Germany in the crucial period between the end of the Third Reich and the official inauguration of the German Democratic Republic (GDR) in 1949. Alexey Tikhomirov has observed that lack of agreement about what form a new, socialist 
Germany would take in 1945, and particularly about how such a hypothetical state would reconcile German political traditions with the process of "Sovietization," led to several conflicts over who loyal East German socialists should promote as their heroes and how to go about such promotion. In the early years of the Soviet occupation, East German communists were able to promote their own leaders, such as Wilhelm Pieck, often at the expense of the Soviets, and they avoided large-scale emulation of the Stalin cult. Just as the "peace movement" stressed Wang's Chineseness, these early postwar communists sought to emphasize their autonomy by promoting distinctly German heroes under the early period of Soviet occupation, while balancing this with the reality of Soviet power. Similarly, and as with occupied China in the lead-up to and just after the creation of the RNG, they were able to do so because of an "absence of a system of centralized control over visual agitation" in the years just before the founding of the GDR.91 In both cases, a general confusion that characterized the early stage of occupation, and a lack of agreement about what the occupation would develop into, led to the rise of short-lived personality cults authored almost exclusively by Germans and Chinese, respectively. In East Germany, this continued until large-scale Sovietization in 1949; in Wang's RNG, it was undermined by events that followed the Pearl Harbor attack and the confused messages that attack produced in RNG propaganda from 1941 onward. In both cases, the changing context of occupation undermined the consistency of the message.

Only in recent years has the Wang Jingwei personality cult has been taken seriously as a subject of academic inquiry. Like the RNG itself, it has often been dismissed as nothing more than the detritus of Japanese militarism. The postwar dismantling of the Wang cult was made easier, ironically, by the RNG's avoidance of widespread architectural, sculptural, or nomenclatural references to its leader, and this also contributed to its erasure from public memory in China.92 Study of the regime is also hindered by a dearth of archival evidence that was left in Japan at the 
end of the Second World War, and more recently by the indefinite closure of Number Two Historical Archives in Nanjing, which holds many important sources for studying the RNG. I hope this institution will eventually reopen, and enable others to test the arguments I make in this paper.

The Wang cult deserves to be studied for more than what it says about wartime China. In its contradistinction from the Nationalist promotion of Chiang Kai-shek, its development in the absence of a state propaganda framework, and in the ultimately contradictory messages that it came to promote, the Wang Jingwei personality cult offers a window into political cultures that develop under the rubric of collaboration. 
Abstract: This paper explores the development of the Wang Jingwei personality cult during the Japanese occupation of China (1937-1945). It examines how the collaborationist Chinese state led by Wang sought to distinguish its figurehead from the person he had replaced, Nationalist leader Chiang Kai-shek. Drawing on visual, archival, and published sources, it traces the development of the Wang cult from the early years of the war, and argues that the unusual context in which the cult evolved ultimately undermined its coherence. The case of Wang Jingwei illustrates how the Chinese case more broadly can enhance our understandings of personality cults that develop under occupation. To this end, I compare the Wang regime with various European "collaborationist" governments that sought to promote their leaders in similar ways. 
1 Jan Plamper, The Stalin Cult: A Study in the Alchemy of Power (New Haven: Yale University Press, 2012), 14-15.

2 Christopher Duggan, "The Propagation of the Cult of the Duce, 1925-26," in Stephen Gundle, Christopher Duggan, and Giuliana Pieri, eds., The Cult of the Duce: Mussolini and the Italians (Manchester: Manchester University Press, 2013), 27-40.

3 Daniel Leese, Mao Cult: Rhetoric and Ritual in China's Cultural Revolution (Cambridge: Cambridge University Press, 2011), 11; Raymond F. Wylie, The Emergence of Maoism: Mao Tse-tung, Ch'en Po-ta, and the Search for Chinese Theory, 1935-1945 (Stanford: Stanford University Press, 1980), esp. 126-27.

4 This earlier scholarship is well summarized in Wang Ke-wen, "Irreversible Verdict? Historical Assessments of Wang Jingwei in the People's Republic and Taiwan," Twentieth-Century China 28, 1 (2002): 57-81.

5 David P. Barrett, “The Wang Jingwei Regime, 1940-1945: Continuities and Disjunctures with Nationalist China,” in D. Barrett and Larry N. Shyu, eds., Chinese Collaboration with Japan, 1932-1945: The Limits of Accommodation (Stanford: Stanford University Press, 2001), 105.

6 One example is Tian Wenyi, Yu gui wei ling: Jiang jieshi yu Wang Jingwei de banian shengsi zhan (The devil next door: the eight-year life and death war between Chiang Kai-shek and Wang Jingwei) (Beijing: Taiwan chubanshe, 2010).

7 Jeremy E. Taylor, "The Production of the Chiang Kai-shek Personality Cult, 1939-1975," China Quarterly 185 (2006): 96-110.

8 To borrow another term from Plamper, Stalin Cult

9 Chiang took on a number of mantles in this period, but was not officially China's head of state. 
From 1931, the Republic of China's head of state, or "chairman," was Lin Sen, who retained the position until his death in 1943.

10 Parks M. Coble, “The Legacy of China's Wartime Reporting, 1937-1945: Can the Past Serve the Present?" Modern China 36, 4 (2010): 435-60, 440.

11 Fang Shaoyun, "Yu" (Foreword), in Zuigao lingxiu kangzhan yanlunji (A collection of the supreme leader's speeches on the War of Resistance) (Guangzhou: Guangzhou Tebie Shidangbu, 1938), 1.

12 Stephen R. MacKinnon, Wuhan, 1938: War, Refugees, and the Making of Modern China (Berkeley: University of California Press, 2008), 78-79.

13 Beifa shishi di shi er zhou nian jinian xuanchuan da wang (Twelfth anniversary of the pledge to the Northern Expedition) (n.p.: PDMAC, 1938).

14 Jiang Zongsiling Beifa wengao (Essays on the Northern Expedition) (Nanjing: n.p., 1928); National Institute of Defense Studies (NIDS) (Tokyo): Shina jihen zenpan (Full files on China Incident), 171: Shina jihen senden shiryō (China Incident propaganda material).

15 "Manhuajia Jiuwang Xiehui Xuanchuandui zai Nanjing” (The propaganda corps of the Salvationist Cartoonists Association in Nanjing), Kang Ri huabao (Sino-Japanese War extra), 26 Sept. 1937: 17-18.

16 Lyman P. Van Slyke, Enemies and Friends: The United Front in Chinese Communist History (Stanford: Stanford University Press, 1967), 94.

17 "Yan'an minzhong yonghu Jiang Weiyuanzhang dahui" (The masses in Yan'an hold a rally to protect Chairman Chiang), Wenxian (Documents) (1938.12): B2-4.

18 Delin Lai, "Searching for a Modern Chinese Monument: The Design of the Sun Yat-sen Mausoleum in Nanjing," Journal of the Society of Architectural Historians 64, 1 (2005): 22-55, 
$22-24$.

19 On this, see John Fitzgerald, Awakening China: Politics, Culture, and Class in the Nationalist Revolution (Stanford: Stanford University Press, 1996), esp. 24-33. See also Henrietta Harrison, The Making of the Republican Citizen: Political Ceremonies and Symbols in China, 1911-1929 (Oxford: Oxford University Press, 2000), esp. 151-60.

20 This included new and hastily edited collections of Chiang's wartime admonitions, but also republications of much earlier works by or about Chiang. In 1939, for instance, forty thousand copies of Lingxiu zuijin yanlunji (A collection of speeches by the leader) were produced by the PDMAC, along with other booklets with didactic titles such as Fucong lingxiu. Details are in PDMAC, Yinian lai yiban xuanchuanpin suokan (Collection of ordinary propaganda publications produced over the last year) (n.p.: PDMAC, ca. 1938), 10.

21 Philip Jowett, Soldiers of the White Sun: The Chinese Army at War, 1931-1949 (Atglen, Pa: Schiffer, 2011), 203.

22 "Guanyu Zongcai xiaoxiang xian'guafang wei" (On the placement of portraits of the president), Sifa xingzhengbu, Academia Historica, Taipei, 022000000189A/151/189.

23 Robert Payne, Chungking Diary (London: Heinemann, 1945), 113.

24 Harrison, Making of the Republican Citizen, 136-37.

25 Jiang Hao, "The KMT Reorganization Faction and Its Activities in Shanghai," Chinese Studies in History 27, 1-2 (1993): 123-30.

26 Howard L. Boorman, "Wang Ching-wei: China's Romantic Radical," Political Science Quarterly 79, 4 (1964): 504-25, 505.

27 Sven Ugelvik Larsen, "Charisma from Below? The Quisling Case in Norway," Totalitarian Movements and Political Religions 7, 2 (2006): 235-44. 
28 John Hunter Boyle, China and Japan at War, 1937-1945: The Politics of Collaboration (Stanford: Stanford University Press, 1972), 277-305.

29 One of the first examples of a quasi "collected works" was Wang Jingwei Xiansheng Zhongyao Jianyi (Important suggestions by Mr. Wang Jingwei) (Hong Kong: Nanhua Ribao, 1939), a collection of essays either by Wang or by others in praise of his decision to leave Chongqing.

30 Se yanjing (Colored spectacles) (Beijing: Xinminhui, 1939). Hoover Institution Archives, David Nelson Rowe Papers, 78064, box 10.

31 Wu guo de jiushi maiguonu. Minzhong tongku kewang heping: Cushi Dangdufanxing, (Those who harm the nation are the traitorous slaves. The people are suffering and thirst after peace: [we] urge the party to seriously reflect [on the matter]) (n.p., ca. 1939), propaganda leaflet, British Museum, 2006,0117, 23.

32 Chiu, Ming-wah, "Resistance, Peace and War: The Central China Daily News, the South China Daily News and the Wang Jingwei Clique during the Sino-Japanese War, 1937-1945," MA thesis, Department of History, University of Hong Kong, 2005, 111.

33 On this, see Boyle, China and Japan at War, 286-87.

34 Andrew Cheung, "Slogans, Symbols, and Legitimacy: The Case of Wang Jingwei's Nanjing Regime," Indiana East Asia Working Paper Series 6 (1995).

35 Lars-Erik Nyman, “Sinkiang 1934-1943: Dark Decade for a Pivotal Puppet,” Cahiers du monde russe et soviétique 32, 1 (1991): 97-105, 99.

36 Some of these survive among the David Nelson Rowe papers at the Hoover Institution Archives at Stanford University. See also D. N. Rowe, "Japanese Propaganda in North China, 1937-1938," Public Opinion Quarterly 3, 4 (1939): 564-80, 570. 
37 Boyle, China and Japan at War, 200.

38 American Information Committee, Japan's Cultural Aggression in Asia: A General Study of Methods and Results (Shanghai: American Information Committee, 1939), 13.

39 On the day the RNG was proclaimed, Lin Bosheng's Zhonghua Ribao carried advertisements for "Old Du's" brand of eye drops (Lao Feng yanyao), which featured a lithograph image of Wang and read, "The eye drops of the great and famous" (weiren yu mingshi yanyao).

40 Barrett, "Wang Jingwei Regime."

41 Margherita Zanasi, Saving the Nation: Economic Modernity in Republican China (Chicago: University of Chicago Press, 2006), 209.

42 Boyle, China and Japan at War, 26.

43 For an example of such lists published in Chongqing, see Di'erqi kangzhan biaoyu (Slogans for the second phase of the War of Resistance) (Chongqing: Zhongguo guomindang zhixing weiyuanhui xuanchuanbu, 1939).

44 "Wang zhuxi yuzhao zeng yu Chaoxian ge qiaoxiao" (Portraits of Chairman Wang given to overseas Chinese schools in Korea), Xing Ya yuebao (Revive Asia monthly) 1, 1 (1942): 34.

45 Chinese in the occupied Philippines, for instance, were asked by the Japanese to stamp on portraits of Chiang Kai-shek while shouting, "Wang Jingwei wan sui" (Long live Wang Jingwei). George Henry Weightman, “The Philippine Chinese: A Cultural History of a Marginal Trading Community," PhD diss., Department of Sociology, Cornell University, 1960, 99.

46 Li Jie, "Phantasmagoric Manchukuo: Documentaries Produced by the South Manchurian Railway Company, 1932-1940," Positions: East Asia Cultures Critique 22, 2 (2014): 329-69, 346.

47 Thomas David Dubois. "Rule of Law in a Brave New Empire: Legal Rhetoric and Practice in 
Manchukuo," Law and History Review 26, 2 (2008): 293-95.

48 Lin Bosheng, "Kaimu ci” (Opening remarks), in Xuanchuanbu diyijie quanguo xuanchuan huiyi shilü (Record of the Ministry of Propaganda's First National Propaganda Meeting) (Nanjing: Xuanchuanbu, 1941), 25.

49 Christopher Lloyd, Collaboration and Resistance in Occupied France: Representing Treason and Sacrifice (London: Palgrave Macmillan, 2003), 57.

50 Lin Bosheng, "Wang Xiansheng zhi zhongyao jianyi” (The important suggestions of Mr. Wang), in Wang Jingwei Xiansheng Zhongyao Jianyi (Important suggestions by Mr. Wang Jingwei) (Hong Kong: Nanhua Ribao, 1939), 11

51 This is based on my examination of the extensive photographic record produced by the RNG state itself held by Academia Historica in Taipei, which is cited throughout this paper. These images provide valuable insight into ways in which the RNG pictorially represented itself. Unfortunately, reproduction of them is not allowed.

52 Gerald E. Bunker, The Peace Conspiracy: Wang Ch'ing-wei and the China War, 1937-1941 (Cambridge: Harvard University Press, 1972), 9.

53 The much-publicized meeting between Wang and other collaborationist leaders in Qingdao at the end of January 1940 was indicative of this. Dōmei newsreels showed a charismatic Wang dressed in a Western lounge suit, jovially discussing the structure of this new government. "New China’s Big Three Meet Tsingtao," 5 June 1940, UCLA Film and Television Archive, VA17323. 54 On this, see Laura Tyson Li, Madame Chiang Kai-shek: China's Eternal First Lady (New York: Atlantic Monthly Press, 2006).

55 Chen Yunqian, "Minguo Zhongshan Lu yu yishi xingtai richanghua” (Zhongshan roads in Republican China, and the regularization of ideology), Shixue yuekan (Historical studies) 12 
(2007): 113.

56 "Wang Zhaoming jieshou qingxiang gongzuo renyuan zhuzeng tongxiang” (Wang Jingwei accepts a bronze bust made by a rural pacification worker), undated photo, Wang Zhaoming shiliao, Academia Historica, Taipei, 118-030400-0001-013.

57 Note from Wang Jingwei to Li Shiqun, 1 Mar. 1943, Wang Zhaoming shiliao, Academia Historica, Taipei, 18-010100-0047-070.

58 "Wang ni Jingwei ye pa yi chou" (Turncoat Wang fears his own stinking legacy), Su xun (Suzhou news) 478 (1943): 9.

59 Bunker, Peace Conspiracy, 231.

60 Ibid.

61 Nicholas Atkin, Pétain (London: Longman, 1998), 110.

62 Jiang Hao, "KMT Reorganization.”

63 Anna von der Goltz and Robert Gildea, "Flawed Saviours: The Myths of Hindenburg and Petain,” European History Quarterly 39, 3 (2009): 439-64, 440.

64 American reports from the summer of 1939 suggest that even at this early stage the figure of Sun was central to the promotion of Wang. See Doris Rubens, "Japanese Propaganda Efforts in Shanghai," China Weekly Review, 12 Aug. 1939.

65 "Xuanchuan yaodian di liushi'er hao" (Main points on propaganda, number 62), 28 Mar. 1942, Shanghai Municipal Archives, R18-1-54.

66 It appears that the figure of Sun was so sacred that even when such comparisons were made they were distanced. In this instance, the author suggests "in the eyes of most Japanese people." Chen Ming, "Wang zhuxi fendou shi” (A history of Chairman Wang's struggle), Zhongguo manhua (Chinese cartoons) 1 (1942): 29. 
67 Andrew Cheung is one of the few scholars to have examined the importance of Sun in this cult in detail; "Slogans, Symbols, and Legitimacy."

68 "Wang Xiansheng wei guofu zhuxi” (Mr. Wang is the chairman of the National Government), Xin Dongfang zazhi 2 (1940.4): 7-8.

69 This theme is explored in some depth in Margherita Zanasi, "Globalizing Hanjian: The Suzhou Trials and the Post-World War II Discourse on Collaboration," American Historical Review 113, 3 (2008): 731-51.

70 Chris Pearson, Scarred Landscapes: War and Nature in Vichy France (London: Palgrave, 2008), 58-59.

71 On the reconfiguring of Nanjing as a monument to Sun Yat-sen, see Harrison, Making of the Republican Citizen, 208-14.

72 Rudolf G. Wagner, "Ritual, Architecture, Politics, and Publicity during the Republic: Enshrining Sun Yat-sen," in Jeffrey Cody, Nancy S. Steinhardt, and Tony Atkin, eds., Chinese Architecture and the Beaux-Arts (Honolulu: University of Hawai`i Press, 2011), 264-65.

73 Boyle, China and Japan at War, 306-7.

75 Guofu huandu di'er nian guomin zhengfu shizheng gaikuang (The current state of affairs in the second year following the return of the National Government) (Nanjing: Xuanchuanbu, 1942). 76 An example is Rana Mitter, "Contention and Redemption: Ideologies of National Salvation in Republican China," Totalitarian Movements and Political Religions 3, 3 (2002): 44-74.

77 Barrett, “Wang Jingwei Regime,” 105.

78 "Wang zhengfu zhuxi Wang Zhaoming canguan Beiping kongmiao" (Chairman of the RNG, Wang Jingwei, visits the Confucius Temple in Beijing), photo, 20 Oct. 1942, Wang Zhaoming shiliao, Academia Historica, Taipei, 118-030200-0002-007. 
79 Leese, Mao Cult, 11.

80 Ling Mu, "Wang Jingwei zhuyi yu xin guomin yundong” (Wang Jingwei-ism and the New Citizens Movement), in Zhu Jinyuan, ed., Wang Jingwei guomin zhengfu qingxiang yundong (The rural pacification movement of the Wang Jingwei National Government) (Shanghai: Xinhua shudian, 1985), 381-83. This article was first published in April 1942.

81 Wang Jingwei has been absent from the academic literature on Mao badges in 1960s-1970s China. That the RNG made use of such "cult products" in the mid-1940s may indicate that debates over the origins of the Mao badge need to be revisited.

82 "In many of the advanced countries around the world," read instructions from the ministry, "almost every single person wears an image of their leader out of respect. Why is it that even in this minor issue we are unable to keep up?"6 June 1943, Shanghai Municipal Archives, R48-H112.

83 Wang Kewen, "Wang Jingwei zuihou zhi xinqing” (Wang Jingwei’s last sentiments), Dangdai (Contemporary) 155 (2000.7): 50.

84 Paul M. A. Linebarger, The China of Chiang Kai-shek (Boston: World Peace Foundation, 1941), 265.

85 Jay Taylor, The Generalissimo: Chiang Kai-sek and the Struggle for Modern China (Cambridge: Belknap Press, 2009), 259-61.

86 Philip Jaffe, "The Secret of China's Destiny," in Chiang Kai-shek, China's Destiny and Chinese Economic Theory (London: Dennis Dobson Ltd., 1947), 19.

87 Leese, Mao Cult, 11.

88 "Guanyu Zongcai xiaoxiang..." (On the hanging of the president's portrait...), 19 Nov. 1943, Sifa Xingzhengbu, Academia Historica, Taipei, 022000000189A, 151/189.

89 "Guofu yixiang ji zhuxi xiaoxiang zhizuo shenqing shencha ban fa" (Regulations on the 
request for the reproduction of portraits of Sun Yat-sen and Chiang Kai-shek), 11 Dec. 1943, Nationalist Party Archives, Taipei, 5.3/221.9.

90 E. A. Rees, "Leader Cults: Varieties, Preconditions and Functions," in Balázs Aporm, J. C. Behrends, P. Jones, and E. A. Rees, eds., The Leader Cult in Communist Dictatorships: Stalin and the Eastern Bloc (London: Palgrave Macmillan, 2004), 4-5.

91 Alexey Tikhomirov, "Symbols of Power in Rituals of Violence: The Personality Cult and Iconoclasm on the Soviet Empire's Periphery (East Germany, 1945-61),” Jacqueline Friedlander, trans., Kritika 13, 1 (Winter 2012): 47-88.

92 Ironically, and as Ke-wen Wang has pointed out, contradistinction was also at play in this process, for "destroying Wang's place in history was necessary to the establishment of Jiang [Chiang Kai-shek] as the legitimate, and only, heir to Sun Yat-sen...." Ke-wen Wang, “Irreversible Verdict? Historical Assessments of Wang Jingwei in the People's Republic of China and Taiwan," Twentieth-Century China 28, 1 (2002): 57-81, 59. 